\title{
Particle Transport in Fouling Caused by Kaolin-Water Suspensions on Copper Tubes*
}

\author{
L. F. MELO and J. D. PINHEIRO
}

University of Minho - CQPA/INIC, 4700 Braga, Portugal

\begin{abstract}
Particulate fouling tests were carried out using kaolin-water suspensions flowing through an annular heat exchanger with a copper inner tube. The flow rate was changed from test to test, but the fluid temperature and $\mathrm{pH}$, as well as the particle concentration, were maintained constant.

In the lower range of fluid velocities $(<0.5 \mathrm{~m} / \mathrm{s})$, the deposition process seemed to be controlled by mass transfer. The corresponding experimental transport fluxes were compared to the predictions obtained with several models, showing that diffusion governed particle transport. The absolute values of the mass transfer fluxes and their dependences on the Reynolds number were satisfactorily predicted by some of the models.
\end{abstract}

\begin{abstract}
On a effectué des tests d'obturation par des particules à l'aide d'un mélange kaolin-eau s'écoulant à travers un échangeur de chaleur annulaire muni d'un tube intérieur en cuivre. On a fait varier le débit dans les tests, mais la température du fluide, le $\mathrm{pH}$ ainsi que la concentration de particules ont été maintenus constants.

Pour des petites vitesses de fluide $(<0,5 \mathrm{~m} / \mathrm{s})$, la vitesse de dépôt semble être contrôlée par le transfert de matière. Les flux observés expérimentalement correspondants ont été comparés aux prédictions de plusieurs modèles et cela indique que la diffusion gouverne le transport des particules. La valeur absolue des flux de transfert de matière et leur dépendance par rapport au nombre de Reynolds ont été prédites de manière satisfaisante par certains modèles.
\end{abstract}

Keywords: particulate fouling, mass transfer models, particle transport, kaolin-water fouling.

$\mathbf{T}$ ransport, adhesion and removal are the basic processes involved in the build-up of particulate fouling deposits. Evaluation of the transport flux of particles can be, thus, an important step forward in the prediction of overall fouling rates or tendencies.

The models available for predicting mass transfer fluxes in flowing fluids have been applied with greater success to dissolved species than to suspended solids. The equations available for these two-phase flow systems were developed mainly from experimental aerosol studies and have been seldom tested with liquid-solid data. Specific problems arise when the transport step is part of an overall complex fouling phenomenon. In such cases, the processes controlling deposition must be identified in order to evaluate correctly the experimental mass transfer fluxes. Furthermore, in a fouling situation, the roughness of the surface of the deposit is usually different from that of the clean surface, leading to significant variations in the transport rates.

In this work, data from heat transfer fouling tests with liquid suspensions were used to assess several transport models and to identify the type of transport mechanism prevailing.

\section{Particle transport models}

\section{BASIC CONCEPTS}

In the absence of external forces (e.g., gravity), the mass transfer flux $\left(J_{t}\right)$ towards a solid-fluid interface is usually shown to be dependent on Brownian and turbulent diffusion mechanisms, as stated in Fick's first law (adapted):

$$
J_{t}=\left(D_{B}+\epsilon\right) \mathrm{d} C / \mathrm{d} y
$$

*Based on paper presented at Symposium on Fouling of Heat Exchangers, 36th Canadian Chemical Engineering Conference, Sarnia, Ontario, October $5-8,1986$.
The molecular or Brownian diffusivity $\left(\mathfrak{D}_{B}\right)$ decreases with increasing size of molecules or particles. The eddy diffusivity $(\epsilon)$ decreases as the surface is approached, that is, when the particle moves from the turbulent core to the viscous sub-layer. In spite of the traditional concept of a stable laminar sub-layer, several authors (e.g., Lin et al., 1953; Davies, 1966) proposed semi-empirical correlations for $\epsilon$ where the sub-layer was implicitly considered to be disturbed by the interference of turbulent eddies (i.e., $\epsilon>0$ in the sub-layer). The majority of the authors assume there is an equality between the fluid $(\epsilon)$ and the particle $\left(\epsilon_{p}\right)$ turbulent diffusivities.

Equation (1) can then be integrated, leading to a diffusion mass transfer equation of the following type:

$$
J_{t}=k_{t}\left(C_{b}-C_{s}\right)
$$

In such a case, the mass transfer coefficient $\left(k_{t}\right)$ is identical to a diffusion rate coefficient $\left(k_{D}\right)$. If the particles adhere easily to the deposition surface, $C_{s}=0$.

In general, all transport models consider that particles are carried by eddy diffusion from the turbulent core to a zone near the wall. However, depending on the model, the subsequent trajectory towards the deposition surface has been described by different mechanisms such as turbulent and molecular diffusion, particle inertia, turbulent downsweeps, or convection along the flow direction followed by interception by roughness elements.

In aerosol studies (e.g., Wood, 1981), the type of mechanism that determines the transport rate has been associated to the so-called "dimensionless relaxation time" of the particles $\left(t_{p}^{+}\right)$, defined as the time during which the initial velocity of a particle is reduced to zero in a stagnant fluid on account of viscous drag (Stokes) force:

$$
t_{p}^{+}=\left(u^{*}\right)^{2} \cdot \rho_{p} \cdot D_{p}^{2} /(18 \cdot \mu \cdot \nu) \ldots \ldots \ldots \ldots \ldots
$$

For $t_{p}^{+}<0.1$, diffusion is assumed to be the dominant mechanism; for $0.1<t_{p}^{+}<10$, the initial energy imparted 
TABLE 1

Main Features of Some Transport Models

\begin{tabular}{|c|c|c|}
\hline \multirow[b]{2}{*}{ Authors } & Basic mechanisms & \multirow[b]{2}{*}{ Quantitative aspects } \\
\hline & $\begin{array}{l}\text { Deposition } \\
\text { surface }\end{array}$ & \\
\hline $\begin{array}{l}\text { Linton \& Sherwood } \\
\text { (1950) }\end{array}$ & $\begin{array}{c}\text { Eddy } \\
\text { diffusion } \longrightarrow \text { diffusion }\end{array}$ & $\begin{array}{l}\text { - } \epsilon_{p}=\epsilon \\
\text { - Momentum-mass transfer analogy } \\
\text { - } \mathrm{Sh}=k_{t} D / D_{\mathrm{B}}=(f / 2) \operatorname{Re}(\mathrm{Sc})^{1 / 3} \\
J_{t}=k_{t} C_{b}\end{array}$ \\
\hline $\begin{array}{l}\text { C. N. Davies } \\
(1966 ; 1966 a)\end{array}$ & $\begin{array}{c}\text { Eddy } \\
\text { diffusion }\end{array}$ & $\begin{array}{l}-\epsilon_{p}=\epsilon \text { [correl. of C. N. Davies, 1966] } \\
\text { - } y_{i}=v_{i} t_{p}+R_{p} \text {, with } v_{i} \text { equal to the } \\
\text { radial fluctuating fluid velocity at } \\
\text { distance } y_{i}\left(v_{i} \text { depends on the starting }\right. \\
\text { point of free-flight) } \\
\text { - } J_{t}=k_{t} C_{R} \text {, with } \\
k_{t}=1 /\left[\left(1 / v_{i}\right)+\left(1 / k_{D}\right)\right] \\
\text { - } C_{R}=1.22 C_{b} \text { (Liu \& Ilori, 1974). } \\
\text { - } k_{D}=\int_{y_{i}}^{R} \mathrm{~d} y /\left[D_{\mathrm{B}}+\epsilon_{p}\right] \\
-k_{D} \gg v_{i} \text { (inertia control): } J_{t}=v_{i} C_{R} \\
\text { - } k_{D} \ll v_{i} \text { (diffus. control): } J_{t}=k_{D} C_{R}\end{array}$ \\
\hline Model of C. N. Dav & nodified by considering $\epsilon_{p} \neq \epsilon$ & $\begin{array}{l}-\epsilon_{p}=\epsilon+v_{i}^{2} t_{p} \text { [Liu \& Ilori, 1974] } \\
\text { Particle inertia affects its diffusivity. } \\
\text { The term } v_{i}^{2} t_{p} \text { follows the concept of } \\
\text { fluid eddy diffusivity (velocity, } v_{i} \text {, } \\
\text { times distance, } v_{i} t_{p} \text { ) }\end{array}$ \\
\hline Beal (1970) & $\longrightarrow$ Particle & $\begin{array}{l}-\epsilon_{p}=\epsilon \text { [correl. of Lin et al., 1953] } \\
-y_{i}=v_{i} t_{p}+R_{p}, \text { with: } v_{i}=0.9 u^{*} \\
-J_{t}=k_{t} C_{b} \text {, with } k_{t}=1 /\left[\left(1 / v_{p}\right)\right. \\
\left.+\left(1 / k_{D}\right)\right] \\
-v_{p}=0.5 \text { (Brownian motion velocity } \\
+ \text { mean fluid radial velocity between } \\
y_{i} \text { and } R_{p} \text { ) } \\
-k_{D}=\text { (see C. N. Davies) } \\
-k_{D} \gg v_{p} \text { (inertia control): } J_{t}=v_{p} C_{b} \\
-k_{D} \ll v_{p} \text { (diffus. control): } J_{t}=k_{D} C_{b}\end{array}$ \\
\hline $\begin{array}{l}\text { Cleaver \& Yates } \\
(1975 ; 1976)\end{array}$ & $\begin{array}{l}\text { Addy } \\
\text { diffusion each instant, "bursts", and "downsweeps" cover the } \\
\text { deposition surface. Only those particles whose trajectories } \\
\text { fall outside the burst area can reach the surface. }\end{array}$ & 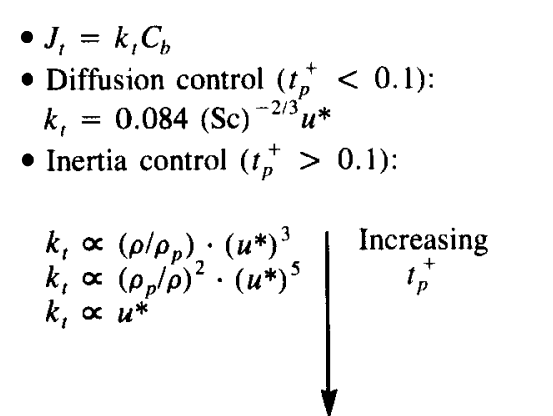 \\
\hline
\end{tabular}


TABLE 1 (Concluded)

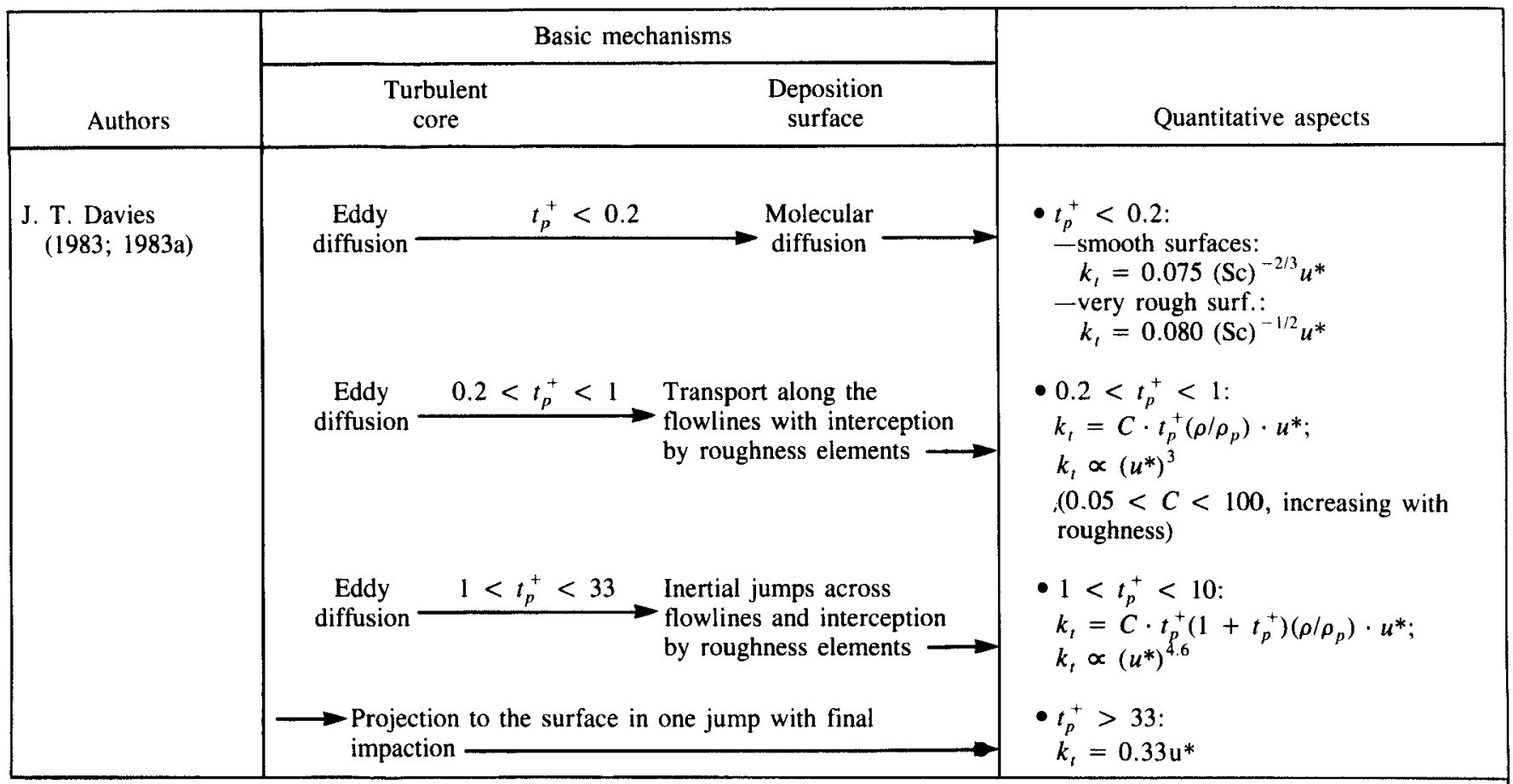

to the particles by the eddies is supposed to make them travel by inertia towards the wall; for $t_{p}^{+}>10$, although particles tend to move at higher velocities, the transport rates of the larger ones in the turbulent core seems to be reduced by their high inertia ("inertia moderated" regime).

\section{SUMMARY OF SOME TRANSPORT MODELS}

Table 1 presents a brief summary of the main features of six transport models for turbulent flow parallel to surfaces. Instantaneous adhesion to the surface, as well as the absence of removal are assumed. Further details on each of these models and reviews on the subject are available in the literature (Montgomery and Corn, 1970; Liu and Ilori, 1974; Newson, 1979; Lister, 1981; Wood, 1981; Beal, 1983; Papavergos and Hedley, 1984; Epstein, 1987). Note that: a) Except for the Linton-Sherwood (1950) pure diffusion equation, the models consider that turbulence plays a role within the sub-layer (however, different correlations are used for the eddy diffusivity, giving different values for $\epsilon$ in the sub-layer). b) In the diffusion-inertia models, the "free-flight velocity" $\left(v_{i}\right)$ is the velocity imparted to the particles as they leave the eddies and start their inertial motion (or freeflight) towards the wall, whereas $y_{i}$ is the distance the particles travel in free-flight and $v_{p}$ (in Beal's model) is the average velocity during the inertial motion. c) The density ratio $\left(\rho / \rho_{p}\right)$ is taken into account only in the models of Cleaver and Yates and of J. T. Davies.

\section{PREVIOUS DATA}

There are few experimental data on hydrosols where the deposition process was not affected (controlled) by adhesion, that is, where the "sticking probability" of the particles could be considered equal to 1 . Amongst the available data, very few are suitable for the purpose of comparing experimental transport fluxes to the ones predicted by the models.

The results of Thomas (1973) obtained in tests with pressurized magnetite-water flowing suspensions were reviewed by Gudmundsson (1981) who found that the experimental values for the $20-50 \mu \mathrm{m}$ particles fell in the "inertiamoderated" regime $\left(t_{p}^{+}>10\right)$ and were substantially lower than the theoretical predictions. The deposition flux $\left(\phi_{d}\right)$ was shown to increase with the Reynolds No. to the power 1 , which is in accordance with the explicit predictions of Cleaver-Yates and of J. T. Davies for high $t_{p}^{+}$.

The data of Burrill (1977), with magnetite-water suspensions, indicate dependences of $\phi_{d}$ on $\operatorname{Re}^{6}$ for low velocities and on $\mathrm{Re}^{0.8}$ for high velocities (high $t_{p}^{+}$), which follow the trends predicted by the two last models in Table 1 for $t_{p}^{+}>0.1-0.2$. Although the average particle diameter and, thus, $t_{p}^{+}$, were not clearly determined by Burrill, he suggested $D_{p}=1 \mu \mathrm{m}$. (For a somewhat greater $D_{p}$ (about $1.5 \mu \mathrm{m})$, the range of $t_{p}^{+}$covered by his experiments goes from 0.1 to 35 ). However, the large difference between the absolute values of the deposition flux obtained with nickel and with zircaloy surfaces appears to be quite an awkward result, since it suggests an adhesion controlled process (in which $\phi_{d}$ would not be expected to increase with the fluid velocity...).

Hussain (1982) and Newson et al. (1983) presented results that show a great scatter. Mass transfer seems to control the deposition process and the authors state that $\phi_{d}$ is proportional to $\mathrm{Re}^{n}$, with $n=0.5-1.0$. Values of $t_{p}^{+}$for these tests $(\$ 0.1)$ are all in the diffusion regime and can be reasonably described by the diffusion equation of Cleaver and Yates.

The data of Watkinson and Epstein (1970), obtained using sand-water suspensions, followed the diffusion-type relationship in the region of mass transfer controlled deposition, but the individual values were presented in thermal resistance units and cannot be compared to the absolute predictions of the models.

There is a great amount of aerosol data showing that C. N. Davies's model is more adequate for low $t_{p}^{+}(<0.1)$, whereas Beals's model gives more satisfactory results in the inertia regime. The experimental trends are rather well described by the models of Cleaver and Yates and 


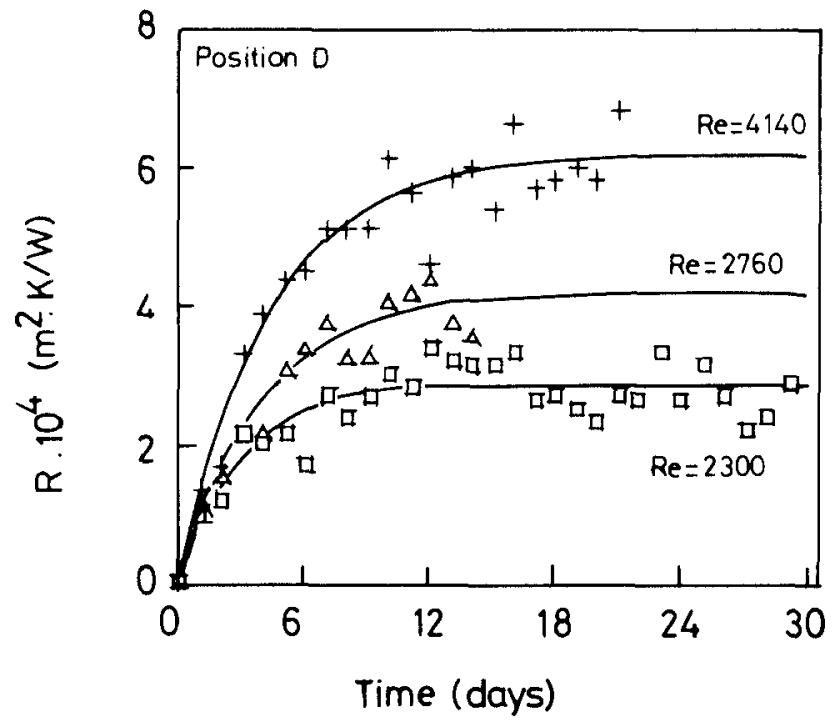

Figure 1 - Fouling data in position D.

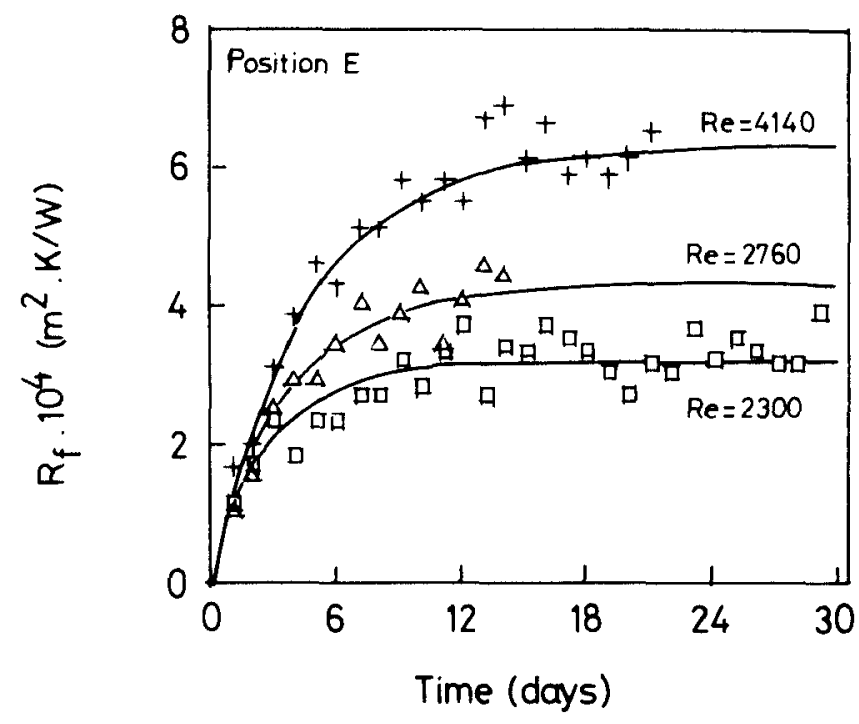

Figure 2 - Fouling data in position E.

of J. T. Davies in the whole range of $t_{p}^{+}$. However, the absolute values predicted by the several models differ often by a factor of one or two from the data.

\section{EQUIPMENT AND METHODS}

Fouling tests were performed in an annular heat exchanger consisting of a 2 meter long external perspex tube $(\mathrm{ID}=36 \mathrm{~mm})$ and a removable inner copper tube $(\mathrm{OD}=$ $25 \mathrm{~mm}$ ) which was electrically heated. Water-kaolin suspensions were circulated through the annular section at different Reynolds numbers (based on the equivalent diameter $0.011 \mathrm{~m}$ ), with concentration $=2.2 \mathrm{~kg} / \mathrm{m}^{3}$ and $\mathrm{pH}=7.5$. The kaolin particles were studied with a laser flow granulometer and a scanning electron microscope (SEM) and can be roughly described as thin discs with $16 \mu \mathrm{m}$ (mean diameter) by $1 \mu \mathrm{m}$ (mean thickness). SEM visualization of the deposits formed on the copper surfaces showed that the particles adhere by their larger faces (the bases of the discs).

Temperatures of the fluid $\left(12^{\circ} \mathrm{C}\right)$ and of the copper tube, as well as heat fluxes $\left(3000 \mathrm{~W} / \mathrm{m}^{2}\right)$ and pressure drops were measured, allowing the evaluation of the local thermal

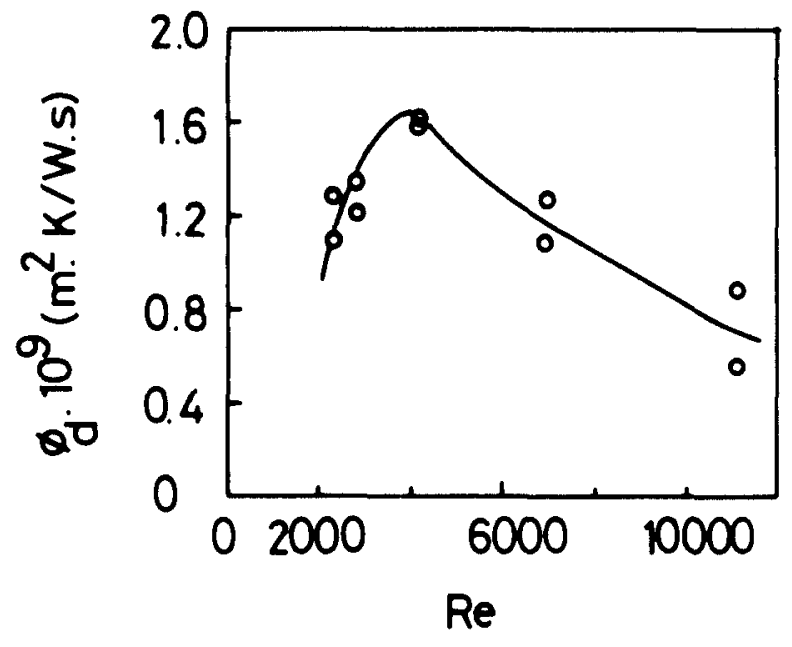

Figure 3 - Deposition flux versus Reynolds No.

TABLE 2

Parameters of the Asymptotic Fouling Model-Experimental Values

\begin{tabular}{lllllll}
\hline Reynolds number & & 2300 & 2760 & 4140 & 6900 & 11040 \\
Fluid velocity $(\mathrm{m} / \mathrm{s})$ & & 0.26 & 0.32 & 0.48 & 0.79 & 1.30 \\
Local $R_{f}^{\infty} \cdot 10^{4}$ & D & 2.9 & 4.2 & 6.2 & 5.0 & 3.0 \\
$\quad\left(\mathrm{~m}^{2} \cdot \mathrm{K} / \mathrm{W}\right)$ & E & 3.2 & 4.3 & 6.3 & 5.0 & 1.6 \\
Local $\phi_{d} \cdot 10^{9}$ & D & 1.11 & 1.21 & 1.58 & 1.28 & 0.90 \\
$\left(\mathrm{~m}^{2} \cdot \mathrm{K} / \mathrm{W} \cdot \mathrm{s}\right)$ & E & 1.30 & 1.35 & 1.62 & 1.10 & 0.56 \\
Local $1 / \beta \cdot 10^{-6}$ & D & 0.26 & 0.35 & 0.39 & 0.39 & 0.33 \\
$(\mathrm{~s})$ & E & 0.25 & 0.32 & 0.39 & 0.45 & 0.29 \\
\hline
\end{tabular}

resistances of the kaolin deposits during the build-up process (Melo and Pinheiro, 1986). The thermal conductivity of the deposit $\left(k_{f}=0.17 \mathrm{~W} / \mathrm{m} \cdot \mathrm{K}\right)$ could be determined measuring its final thickness and thermal resistance. The density of the deposits $\left(\rho_{f}=420 \mathrm{~kg} / \mathrm{m}^{3}\right)$ was evaluated from thickness and weight measurements.

\section{Results and discussion}

Figures 1 and 2 show the fouling data obtained at two different axial positions in the heat exchanger ( $D$ and $E$, both in the fully developed flow region), for the lower range of Reynolds numbers. These data were fitted by the usual asymptotic fouling equation (curves shown in the Figures):

$$
R_{f}=R_{f}^{\infty}[1-\exp (-\beta \cdot t)]
$$

from which the values of the asymptotic fouling resistance $\left(\boldsymbol{R}_{f}^{\infty}\right)$, the deposition flux $\left(\phi_{d}=\beta \cdot \boldsymbol{R}_{f}^{\infty}\right)$ and the "resistance to removal"' $(1 / \beta)$ were calculated - see Table 2 .

The effect of the Reynolds No. on $\phi_{d}$ is illustrated in Figure 3. These results suggest that mass transfer controls the deposition rate for $\mathrm{Re}<3900$, adhesion being the dominant process for higher values of $\mathrm{Re}$. Therefore, the transport flux $\phi_{t}$ is assumed to be equal to $\phi_{d}$, which can be evaluated in mass units by:

$$
J_{t}=\phi_{t} \cdot \rho_{f} \cdot k_{f}
$$

Values of the mass transfer fluxes predicted by different models are shown in Table 3, together with values obtained from the experimental curve of Figure 3 in the region of mass transfer control. Thermophoretic effects were not considered in this study since the heat flux and the temperature gradients 
Table 3

Mass Transfer Flux: Predictions and Experimental Results

\begin{tabular}{lcccc}
\hline & \multicolumn{3}{c}{$J_{t} \cdot 10^{7}\left(\mathrm{~kg} / \mathrm{m}^{2} \cdot \mathrm{s}\right)$} & \\
\cline { 2 - 4 } \multicolumn{1}{c}{ Models } & $\mathrm{Re}=2300$ & $\mathrm{Re}=2760$ & $\mathrm{Re}=3850$ & (from $J_{t} \propto \mathrm{Re}^{n}$ ) \\
\hline Linton-Sherwood & 0.41 & 0.46 & 0.59 & 0.74 \\
C. N. Davies & 0.51 & 0.62 & 0.88 & 1.0 \\
C. N. Davies modified & 0.43 & 0.53 & 0.87 & 1.4 \\
Beal & 0.36 & 0.44 & 0.71 & 1.2 \\
Cleaver-Yates (diffus.) & 0.44 & 0.51 & 0.68 & 0.85 \\
J. T. Davies (diffusion) & 0.39 & 0.46 & 0.61 & 0.86 \\
Experimental curve & 0.80 & 0.96 & 1.16 & 0.73 \\
\hline
\end{tabular}

TABLE 4

Dimensionless Relaxation Times and Free-Flight Distances of the Kaolin Particles

\begin{tabular}{cccc}
\hline & $\mathrm{Re}=2300$ & $\mathrm{Re}=2760$ & $\mathrm{Re}=3850$ \\
\hline$t_{p}^{+}$ & 0.0020 & 0.0027 & 0.0048 \\
$y_{i}^{+}$ & 0.0083 & 0.0097 & 0.0131 \\
$R_{p}^{+}$ & 0.0083 & 0.0097 & 0.0130 \\
\hline
\end{tabular}

were low. The dependences of $J_{t}$ on $\operatorname{Re}$ (parameter $n$ ) were estimated by linear regression analysis (correlation coefficients $>0.99$, except for C. N. Davies's model).

The equations of the models were used with the following conditions: a) in the evaluation of the free-flight distance $\left(y_{i}\right) R_{p}$ was replaced by the half-thickness of the particles $(0.5 \mu \mathrm{m}) ; \mathrm{b})$ an "equivalent particle diameter" (7 $\mu \mathrm{m})$, defined as the diameter of the sphere with a volume equal to the volume of the particle, was used in the calculation of the relaxation time and of the Brownian diffusivity (with $\rho_{p}$ $\left.=2600 \mathrm{~kg} / \mathrm{m}^{3}\right) ; \mathrm{c}$ ) experimental friction factors at the inner surface of the fouled annulus were estimated (see Melo and Pinheiro, 1985) and correlated by the expression $f=0.093$ $\operatorname{Re}^{-0.26}$. The Linton-Sherwood equation thus became:

$$
\mathrm{Sh}=0.0465 \mathrm{Re}^{0.74} \cdot \mathrm{Sc}^{1 / 3} \ldots \ldots \ldots \ldots \ldots \ldots \ldots
$$

All the models yielded mass transfer fluxes values that are close to the experimental ones but the predicted dependences of $J_{t}$ on $\operatorname{Re}$ (values of $n$ in Table 1) differ from model to model. The best agreement between experimental and theoretical values of $n$ is given by the models of LintonSherwood, Cleaver-Yates, and J. T. Davies, which are the more "diffusion-oriented" equations.

Table 4 shows the dimensionless relaxation times and freeflight distances of the particles for different Reynolds numbers as well as the dimensionless particle half-thickness $\left(R_{p}^{+}\right) \cdot t_{p}^{+}$is always much lower than 0.1 , indicating that a diffusion mechanism will determine the transport rates. Also, the free-flight distance is equal to the particle half-thickness and much smaller than the thickness of the sub-layer $\left(y^{+}=5\right)$, which means that transport by inertia is highly improbable.

The experimental values of the transport flux are, in every case, greater than the theoretical ones. This could be due to roughness effects, that are difficult to estimate with accuracy in this type of tests and have not yet been properly included in the models. For instance, the equations of J. T. Davies for "smooth surfaces" and for "very rough surfaces", produce values that are, respectively, half the experimental ones (see Table 3) and 6 times greater than these. The use of a modification of C. N. Davies's model proposed by
Browne (1974) for deposition on rough surfaces is not adequate in the present case, since it gives very high values of $J_{t}$ and of the exponent $n$ (around 3.5).

Relatively high values of $n$ were obtained with those models that apply eddy diffusivity correlations in the sublayer (C. N. Davies, with and without modification, and Beal). Such correlations were not used in the other models, which seems to indicate a possible failure of the eddy diffusivity equations in describing the diffusion mechanism near the wall. According to Lin et al. (1953), $\epsilon$ should increase with $\left(u^{*}\right)^{3}$ in the sub-layer, while in C. N. Davies' correlation the dependence on $u^{*}$ is slightly lower. When the eddy diffusivity of the particle is evaluated using the modification proposed by Liu and Ilori (1974), this dependence is stronger on account of the added effect of $v_{i}^{2}$ on $\epsilon$. Therefore, the differences in $n$ can be, to a certain extent, attributed to the type of eddy diffusivity correlation used in each model.

The relationships proposed by Cleaver-Yates and by J. T. Davies are quite similar, although they were based on different approaches. They seem to give a better description of the transport process since they consider more realistic trajectories of the particles as they approach the wall (not simply perpendicular to the wall) and they take into account the density ratio $\left(\rho / \rho_{p}\right)$. Also they do not rely upon expressions for the eddy diffusivity, nor upon the concept of freeflight distance. Good results were obtained with the classical correlation based on the momentum-mass transfer analogy, where the eddy diffusivity is considered to vanish in the sub-layer. As it appears, the quantitative description of this region is still a key question to be solved.

A final comment should be made regarding the range of Reynolds numbers used in the tests, which lies in the transition flow regime. Since turbulence is already present and the eddy diffusion mechanisms are acting on the particles, a rather similar behaviour should be expected if the flow was fully turbulent. However, the velocity gradient would be steeper and lift force effects could possibly become more important.

\section{Conclusions}

Data from heat transfer fouling tests with kaolin-water suspensions were used in a comparative study of several transport models, in order to assess their validity in the case of deposition from liquid streams. Diffusion was found to be the dominant mechanism of mass transfer and the experimental results (not only the dependence of $J_{t}$ on Re, but also the absolute values of the transport fluxes) were satisfactorily predicted by the models that give better description of the diffusion process in the sub-layer: the "classical" mass 
transfer correlation and the models of Cleaver-Yates and of J. T. Davies. The correlations for the eddy diffusivity did not seem to be very reliable in the region close to the wall, suggesting the need for a more detailed quantitative analysis of the sub-layer. Also, the effect of roughness on the transport flux does not appear to be taken into account properly in the available equations.

\section{Nomenclature}

$C=$ concentration at a distance $y$ from the surface, $\mathrm{kg} / \mathrm{m}^{3}$

$C_{b}=$ bulk (average) concentration, $\mathrm{kg} / \mathrm{m}^{3}$

$C_{R}=$ concentration at the point of maximum velocity, $\mathrm{kg} / \mathrm{m}^{3}$

$C_{\mathrm{s}}=$ concentration at the deposition surface, $\mathrm{kg} / \mathrm{m}^{3}$

$D$ = equivalent diameter of the flow passage, $\mathrm{m}$

$D_{p}=$ particle diameter, $\mathrm{m}$

$\mathfrak{D}_{\mathrm{B}}=$ Brownian (molecular) diffusivity, $\mathrm{m}^{2} / \mathrm{s}$

$f=$ friction factor

$J_{t}=$ mass transfer flux, $\mathrm{kg} / \mathrm{m}^{2} \cdot \mathrm{s}$

$k_{l}=$ diffusion rate coefficient, $\mathrm{m} / \mathrm{s}$

$k_{f}=$ thermal conductivity of the deposit, $\mathrm{W} / \mathrm{m} \cdot \mathrm{K}$

$k_{t}=$ mass transfer (or transport) coefficient, $\mathrm{m} / \mathrm{s}$

$R=$ tube radius, $\mathrm{m}$

$\mathrm{Re}=$ Reynolds number, based on equivalent diameter $(u \cdot D / v)$

$R_{f}=$ thermal resistance of the deposit, $\mathrm{m}^{2} \cdot \mathrm{K} / \mathrm{W}$

$R_{f}^{\infty}=$ asymptotic thermal resistance of the deposit, $\mathrm{m}^{2} \cdot \mathrm{K} / \mathrm{W}$

$R_{p}=$ particle radius or half-thickness, $\mathrm{m}$

$R_{p}^{+}=$dimensionless particle half-thickness

$\mathrm{Sc}=$ Schmidt number $\left(v / D_{\mathrm{B}}\right)$

$\mathrm{Sh}=$ Sherwood number $\left(k_{t} \cdot D / D_{\mathrm{B}}\right)$

$t_{p}=$ relaxation time of the particle, $\mathrm{s}$

$t_{p}^{+}=$dimensionless relaxation time

$u=$ mean fluid velocity, $\mathrm{m} / \mathrm{s}$

$u^{*}=$ friction velocity $(u \cdot \sqrt{f / 2}), \mathrm{m} / \mathrm{s}$

$v_{i}=$ free-flight velocity of the particle, $\mathrm{m} / \mathrm{s}$

$y=$ distance to the deposition surface, $\mathrm{m}$

$y_{i}=$ free-flight distance, $\mathrm{m}$

$y_{i}^{+}=$dimensionless free-flight distance $\left(y_{i} \cdot u^{*} / v\right)$

\section{Greek symbols}

$\epsilon=$ fluid eddy diffusivity, $\mathrm{m}^{2} / \mathrm{s}$

$\epsilon_{p}=$ particle eddy diffusivity, $\mathrm{m}^{2} / \mathrm{s}$

$\phi_{d}=$ deposition flux in thermal units, $\mathrm{m}^{2} \cdot \mathrm{K} / \mathrm{W} \cdot \mathrm{s}$

$\phi_{i}=$ transport flux in thermal units, $\mathrm{m}^{2} \cdot \mathrm{K} / \mathrm{W} \cdot \mathrm{s}$

$\mu=$ dynamic viscosity, $\mathrm{N} \cdot \mathrm{s} / \mathrm{m}^{2}$

$\rho=$ density of the fluid, $\mathrm{kg} / \mathrm{m}^{3}$

$\rho_{f}=$ density of the deposit, $\mathrm{kg} / \mathrm{m}^{3}$

$\rho_{p}=$ density of the particles, $\mathrm{kg} / \mathrm{m}^{3}$

$v=$ kinematic viscosity, $\mathrm{m}^{2} / \mathrm{s}$

\section{References}

Beal, S. K., "Deposition of particles in turbulent flow on channel or pipe walls", Nucl. Sci. Eng. 40, 1-11 (1970).

Beal, S. K., "Particulate fouling of heat exchangers"' in "Fouling of Heat Exchanger Surfaces", R. W. Bryers, Ed., United Engineering Trustees, Inc., N.Y., pp. 215-234 (1983).

Browne, L. W. B., "Deposition of particles on rough surfaces during turbulent gas-flow in a pipe", Atm. Environ. 8, 801-816 (1974).

Burrill, K. A., "The deposition of magnetite particles from high velocity water onto isothermal tubes", Atomic Energy of Canada Ltd., AECL-5308 (1977).
Cleaver, J. D. and B. Y. Yates, "A sub-layer model for the deposition of particles from a turbulent flow", Chem. Eng. Sci. 30, 983-992 (1975).

Cleaver, J. D. and B. Y. Yates, “'The effect of re-entrainment on particle deposition", Chem. Eng. Sci. 31, 147-151 (1976).

Davies, C. N., "Deposition of aerosols from turbulent flow through pipes", Proc. Royal Soc. London, Ser. A, 289, 235-246 (1966).

Davies, C. N., "Brownian deposition of aerosol particles from turbulent flow through pipes"', Proc. Royal Soc. London, Ser. A, 290, 557-562 (1966a).

Davies, J. T., " A new theory of aerosol deposition from turbulent fluids", Chem. Eng. Sci. 38(1), 135-139 (1983).

Davies, J. T., "A new theory of the deposition of colloidal particles from turbulent fluids", Annals of the New York Academy of Sciences, 313-326 (1983).

Epstein, N., "Particulate fouling of heat transfer surfaces: mechanisms and models" in "Fouling Science and Technology", L. F. Melo, T. R. Bott and C. Bernardo, Eds., Martinus Nijhoff Publishers, Netherlands, in press (1988).

Gudmundsson, J. S., "Particulate fouling" in "Fouling of heat transfer equipment", E. F. C. Somerscales and J. G. Knudsen, Eds., Hemisphere Publ. Corp., N.Y., pp. 357-387 (1981).

Hussain, C. I., "Particulate magnetite fouling from flowing suspensions in simulated heat exchanger tubes", Ph.D. Thesis, Univ. Birmingham, U.K. (1982).

Lin, C. S., R. W. Moulton and G. I. Putnam, "Mass transfer between solid wall and fluid streams - mechanism and eddy distribution relationships in turbulent flow", Ind. Eng. Chem. 45(3), 636-640 (1953).

Linton, W. H. and T. K. Sherwood, Chem. Eng. Progr. 46, 258 (1950).

Lister, D. H., "Corrosion Products in Power Generating Systems" in "Fouling of Heat Transfer Equipment", E. F. C. Somerscales and J. G. Knudsen, Eds., Hemisphere Publishing Corp., N.Y., pp. 135-199 (1981).

Liu, B. Y. H. and T. A. Ilori, "Inertial deposition of aerosol particles in turbulent pipe flow", Environm. Sci. Technol. 8(4), 351-356 (1974).

Melo, L. F. and J. D. Pinheiro, "Estimating friction factors in a fouled annulus", Can. J. Chem. Eng. 63, 693-694 (1985).

Melo, L. F. and J. D. Pinheiro, "Particulate fouling: controlling processes and deposit structure", 8th Int. Heat Transfer Conf., Vol. 6, Paper HX-16, S. Francisco, USA, pp. 2781-2786 (1986).

Montgomery, T. L. and M. Corn, "Aerosol deposition in a pipe with turbulent air flow", J. Aerosol Sci. 1, 185-213 (1970).

Newson, I. H., "Studies of particulate deposition from flowing suspension", Proc. Conf. "Fouling-Art or Science?", Univ. Surrey, U.K., 35-81 (1979).

Newson, I. H., T. R. Bott and C. I. Hussain, "Studies of magnetite deposition from a flowing suspension', Chem. Eng. Commun. 20, 335-353 (1983).

Papavergos, P. G. and A. B. Hedley, "Particle deposition behaviour from turbulent flows"', Chem. Eng. Res. Des. 62, 275-295 (1984).

Thomas, D., "Experimental investigation of the deposition of suspended magnetite from the fluid flow in steam generating boiler tubes", Ph.D. Thesis, Technical Univ. Munich (1973).

Watkinson, A. P. and N. Epstein, "Particulate fouling of sensible heat exchangers", 4th Int. Heat Transfer Conf., Vol. 1, Paper HE.1.6, Versailles, France (1970).

Wood, N. B., "A simple method for the calculation of turbulent deposition to smooth and rough surfaces", J. Aerosol Sci. 12(3), 275-290 (1981).

Manuscript received November 20, 1986; revised manuscript received September 15, 1987; accepted for publication September $16,1987$. 